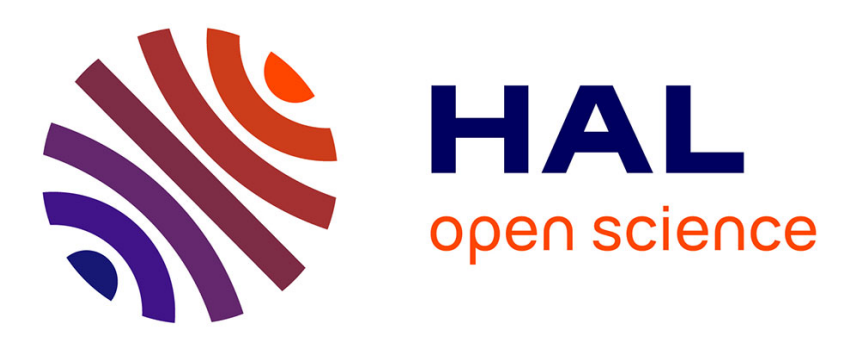

\title{
Behaviour characterisations of sheet metals, metallic honeycombs and foams at high and medium strain rates H. Zhao, G. Gary
}

\section{To cite this version:}

H. Zhao, G. Gary. Behaviour characterisations of sheet metals, metallic honeycombs and foams at high and medium strain rates. Key Engineering Materials, 2000, 177-180, pp.225-230. 10.4028/www.scientific.net/KEM.177-180.225 . hal-00111311

\section{HAL Id: hal-00111311 \\ https://hal.science/hal-00111311}

Submitted on 13 Aug 2019

HAL is a multi-disciplinary open access archive for the deposit and dissemination of scientific research documents, whether they are published or not. The documents may come from teaching and research institutions in France or abroad, or from public or private research centers.
L'archive ouverte pluridisciplinaire HAL, est destinée au dépôt et à la diffusion de documents scientifiques de niveau recherche, publiés ou non, émanant des établissements d'enseignement et de recherche français ou étrangers, des laboratoires publics ou privés. 


\title{
Behaviour Characterisations of Sheet Metals, Metallic Honeycombs and Foams at High and Medium Strain Rates
}

\author{
H. Zhao' and G. Gary ${ }^{2}$ \\ 'Laboratoire de Mécanique et Technologie-Cachan, Université Pierre et Marie Curie (Paris 6), \\ 61, Avenue du Président Wilson, FR-94235 Cachan Cedex, France \\ ${ }^{2}$ Laboratoire de Mécanique des Solides LMS, Ecole Polytechnique, FR-91128 Palaiseau, France
}

Keywords: Aluminium Foam, Honeycomb. Kolsky's Bar, Modelling, Strain Rate

\begin{abstract}
.
This paper deals with dynamic testing and modelling of the metallic materials and soft structural material made of metals such aluminium honeycombs and foams. Tests are performed with the SHPB (Split Hopkinson Pressure Bar) system which is frequently uscd in a range of strain rates which correspond to those involved in most of civil industrial applications. Improvements of the SHPB were necessary in order to obtain reliable results on soft structural materials. Some experimental results and their modelling for metals as well as for aluminium honeycombs and foams will be presented.
\end{abstract}

\section{Material testing with SHPB}

Recently, the industrial requirement of numeric simulations under dynamic loading condition makc the characterisation of the matcrials behaviour under impact loading an important goal for engineers and researchers. The most efficient experimental tool in this field is the Split Hopkinson Pressure Bar (SHPB), or Kolsky's apparatus. Historically, the first use of a long thin bar to measure the pulse shape induced by an impact is considered due to Hopkinson [1]. This method has becn well established after the critical work of Davies [2] The experimental setup with two long bars and a short specimen has been introduced by Kolsky [3].

Kolsky's original SHPB analysis is based on some basic assumptions. (i) The waves propagating in the bars can be described by the one-dimensional wave propagation theory. (ii) The stress and strain fields in the specimen are uniform in its axial direction. (iii) The specimen inertia effect is negligible. (iv) The friction effect in the compression test is also negligible.

Those assumptions have been extensively studied in past decades. Following Davies' works, a more accurate wave propagation theory has been used in the data proccssing. The oscillations due to wave dispersion effects observed in the average stress-strain curve have been diminished. The assumption of axial uniformity of stress and strain fields permits relating the average stress-strain curve to forces and velocities measured at both faces of specimens. Theoretical, experimental, and numerical investigations on this assumption have been reported. It has been proved then that stresses and strains are not axially uniform. However, the average stress-strain relation is quite reliable for metals. In order to minimise friction effects, an optimal length/diameter ratio of the specimen is recommended. Radial and longitudinal inertia effects should be taken into account. The correction, based on the assumption of the axial uniformity of fields, is also proposed. Related references can be found in [4].

\section{Split Hopkinson Pressure Bar Test}

A typical SHPB set-up is composed of long input and output bars with a short specimen placed between them (Fig.1). 


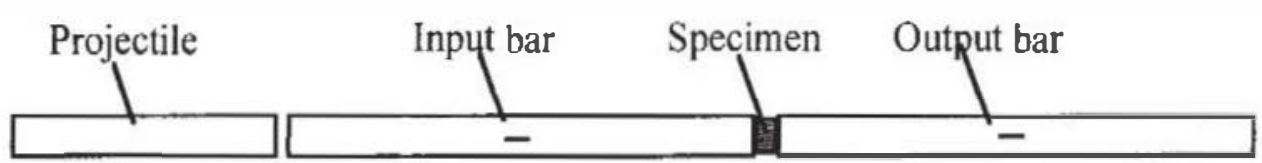

Figure 1. Typical Split Hopkinson P essure Bar setup

The impact of the projectile at the free end of the input bar creates a compressive longitudinal incident wave, $\varepsilon_{\mathrm{j}}(\mathrm{t})$. Once it arrives at the bar-specimen interface, a reflected wave, $\varepsilon_{r}(t)$, is developed in the input bar; a transmitted wave, $\varepsilon_{t}(t)$, is induced in the output bar. From these basic experimental data (incident, reflected and transmitted waves), forces and velocities at both faces of the specimen can be deduced.

$$
\begin{aligned}
& F_{\text {invut }}(t)=S_{h} E_{h}\left(\varepsilon_{i}(t)+\varepsilon_{r}(t)\right) \\
& F_{\text {output }}(t)=S_{b} E_{b} \varepsilon_{t}(t)
\end{aligned} \text { and } \begin{aligned}
& V_{\text {input }}(t)=C_{b}\left(\varepsilon_{j}(t)-\varepsilon_{r}(t)\right) \\
& V_{\text {oupput }}(t)=C_{h} \varepsilon_{r}(t)
\end{aligned}
$$

where $E_{b}, S_{b}, C_{b}$ denote Young's modulus, cross-sectional area, and wave speed of the bar, respectively.

The Split Hopkinson pressure bar arrangement can give then quite accurate measurements of forces and velocities at both sample faces if the data processing is carefully performed. In order to relate material properties to measured forces and velocities at the two specimen faces, the classical analysis assumes the axial uniformity of stress and strain fields in the specimen. An average stress strain curve can be obtained from Eqn. $2 \mathrm{a}$ and $2 \mathrm{~b}$. which lead to the so-called two-waves analysis [2].

$$
\begin{aligned}
& \dot{\varepsilon}_{s}(t)=\frac{V_{\text {oupput }}(t)-V_{\text {input }}(t)}{l_{s}} \\
& \sigma_{s}(t)=\frac{F_{\text {output }}(t)}{S_{s}}
\end{aligned}
$$

where $\dot{\varepsilon}_{s}(t), \sigma_{s}(t), S_{s}, I_{s}$ are respectively average strain rate, stress, cross-sectional area and length of the specimen.

\section{Application to metallic materials}

Application of SHPB to metals deos not arisc particular experimental problems today. However, The material behaviour cannot always be simply derived of the experimental data of SHPB test. For instance, in dynamic tests, strain and stress fields are not homogeneous in space and they are not constant in time [5]. The strain rate during a dynamic test is then not constant and a typical strain rate time history gives a variation of $20 \%$ a ound the average strain rate.

Dynamic tests are not isothermal. A significant temperature increase during the dynamic test is often observed [6]. If the material is thermally sensitive, experimental data (average stress-strain curve, for example) includes necessarily a thermal softening effect. This effect must be taken into account. The temperature increase could be estimated from the plastic work [7], assuming a quasiadiabatic condition and a quasi-complete conversion of plastic work into heat.

For the behaviour modelling of metals, the authors intend to combine the physical concepts with the phenomenological formulation. A simple and directly usable model (with several parameters to identify) is presented and it is associated with identification processes. Such a model is based on the work of Campbell and Ferguson [8] where they indicate that rate and temperature sensitivities of flow stresses can be divided into a few zones. Similar behaviours are observed in each zone for most of metals and alloys. For example, the flow stress increases slightly with the strain rates in zone II (low temperature, low strain rate) where the thermally activated flow mechanism is observed. A sharp increase of flow stress is found in zone IV (low temprature, high 
strain rate) where the viscous drag is dominant. Tanimura [9] has proposed to model material behaviour of metals and alloys by the additive combination of those effects. Following this concept, we propose a model which is a combination of a quasi-static part $\sigma_{s}\left(\varepsilon_{p}, T\right)$, a thermally activated flow part $\sigma_{1}\left(\varepsilon_{p}, \dot{\varepsilon}_{p}, T\right)$ and a viscous drag part $\sigma_{v}\left(\varepsilon_{p}, \dot{\varepsilon}_{p}, T\right)$.

$$
\begin{aligned}
& \sigma_{s}\left(\varepsilon_{p}, T\right)=\left(A+B \varepsilon_{p}^{n}\right)(1-\mu \Delta T) \\
& \sigma_{1}\left(\varepsilon_{p}, \dot{\varepsilon}_{p}, T\right)=\left(C-D \varepsilon_{p}^{\prime \prime \prime}\right) \log \left(\frac{\dot{\varepsilon}}{\dot{\varepsilon}_{0}}\right)(1-\mu \Delta T) \\
& \sigma_{v}\left(\varepsilon_{p}, \dot{\varepsilon}_{p}, T\right)=E \dot{\varepsilon}^{k}(1-\mu \Delta T) \\
& \sigma=\left[A+B \varepsilon_{p}^{n}+\left(C-D \varepsilon_{p}^{m}\right) \log \left(\frac{\dot{\varepsilon}}{\dot{\varepsilon}_{0}}\right)+E \dot{\varepsilon}^{k}\right](1-\mu \Delta T)
\end{aligned}
$$

where $A, B, C, D, E, k, m, n$, and $\dot{\varepsilon}_{0}$ are coefficients of the model.

The parameters of the model for a mild steels (XES) are then obtaincd $(A=145 \mathrm{Mpa}, \mathrm{B}=550$ Mpa $C=35 \mathrm{Mpa}, \mathrm{D}=47 \mathrm{Mpa}, \mathrm{E}=185 \mathrm{Mpa} ; \mathrm{n}=0.42, \mathrm{~m}=0.3, \mathrm{k}=0.3$ ) [10]. The quality of this set of parameters is shown in Figurc 2: where the simulated strain-stress curves using the model with identified parameters and measured strain rate as input data are compared with corresponding experimental curves (the bold lines are experimental curves).

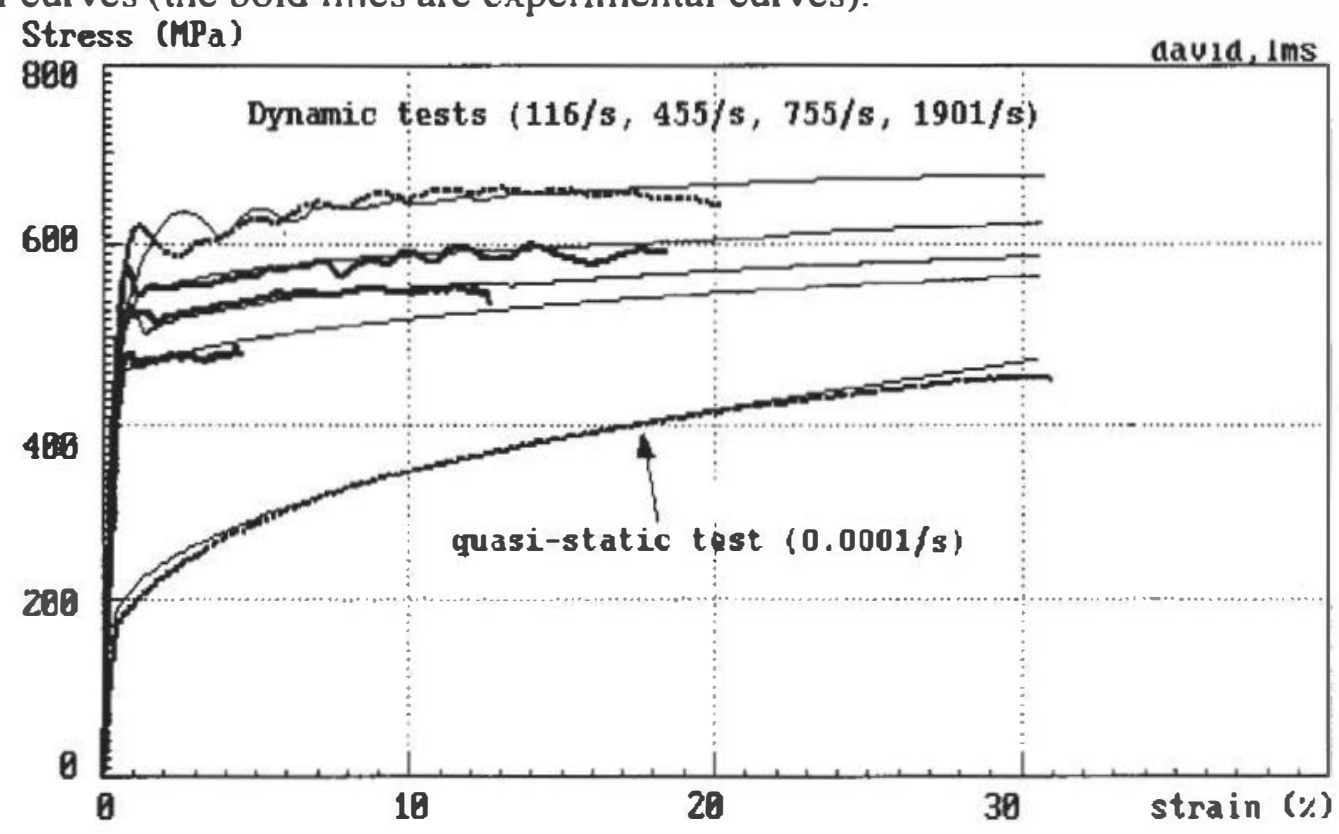

Figure 2. Comparison between model and experimental data

\section{Application to soft materials}

SHPB has been also applied to many non-metallic materials such as concrete [11], rocks, salt-rock, polymers [12] and polymeric foams [13]. Here our interest will be focused on soft structural materials such as aluminium honeycomb and aluminium foam.

\subsection{Specific Problems in soft structural material Testing}

The measuring accuracy of SHPB depends on the amplitude of waves in the bars induced by the resistance of the specimen. Bccause the soft materials such as honeycomb or aluminium foam are quite weak, the induced strain in an ordinary steel Hopkinson bar is smaller than $10^{-6}$. In order to get an accurate measurement, the use of low impedance bars which are generally viscoelastic is proposed. The Nylon bars (Young's modulus $3.5 \times 10^{\prime \prime}$, density $1200 \mathrm{~kg} / \mathrm{m}^{3}$ ) are uscd; they provide an improvement of the measuring sensitivity of about 200 times than that of a classical steel bar. 
However, the use of viscoelastic bars in a SHPB set-up introduces complications rclated to an important wave dispersion effect and requires a special calculation of stress and particle velocity in the bar from the measured strain. The correction of dispersion effects based on the analysis of the wave propagation in an infinite viscoelastic cylindrical bar [14] is used. Using careful data processing, the Nylon bar provides a satisfactory measuring prccision and has been used successfully in testing fibre-reinforced polymeric composite plates [15].

Another particular feature of soft material testing is the need to achieve a large maximum strain (up to $80 \%$ ) for the study of the densification, associated with a significant increase of the stress. Ordinary SHPB arrangements can not measure till such strains, even if such strains arc casily reached because of the very low resistancc of thosc materials. Indeed, measuring technique using bars is based on the superposition principle which implies that the stress, the strain and the particle velocity at any cross-section can be considered as the algebraic sum of thosc valucs associated with the two elementary waves propagating in opposite directions at this cross-section (Eqn 1). Such a technique requircs then a separate recording of each single wave propagating in the bar. This is classically realised by using a long bar and a short pulse to insure the existence of a particular crosssection where those waves are not superimposed. The measuring duration $\tau$ of a given SHPB is then limited by the length of the bars ( $\tau \leq \mathrm{L} / \mathrm{C}, \mathrm{C}$ being the wave speed and $\mathrm{L}$ the length of the bar). Consequently, the measurable crushing displacement is limited for a given impact velocity $\left(\Delta_{\max } \leq \mathrm{V}_{0} \tau\right)$. To overcome this measuring limitation, one has to investigate the multiple reflections in bars [16]. A two-gauge method has been reported to separate the two waves in elastic bars [17] and viscoelastic bar [18]. This two gauges method provides an unlimited measuring duration and gives consequently a sufficient maximum strain.

Furthermore, particular situations in testing such soft materials lead to secondary effects more important than in testing metals. For example, the assumption of uniform stress and strain fields in the specimen can be not verified and an inverse method should be used to obtain a stressstrain relation [19].

\subsection{Rate Sensitivity of Mechanical Behaviours of Honeycombs and Aluminium foams}

Two Nylon ( $\mathrm{Pa} 6.6$ ) bars (3-m length, 40-mm diameter) were used in our tcsts on honeycomb and aluminium foam. For the honeycombs, cubic specimens (about $36 \times 36 \times 36 \mathrm{~mm}$ ) are used. The post-test observations of crushed specimens do not reveal visible differences between static and dynamic loading. The out-of-plane crushing mode ( $x 3$ direction) is a regular multiple localised folding (Fig.3b and Fig.3c-left). For in-plane crushing, a regular folding is observed in the x1-direction (Fig. 3c-center), whereas irregular patterns are found in the x2-direction (Fig.3c-right), similar to those observed by Klintworth and Stronge [20].

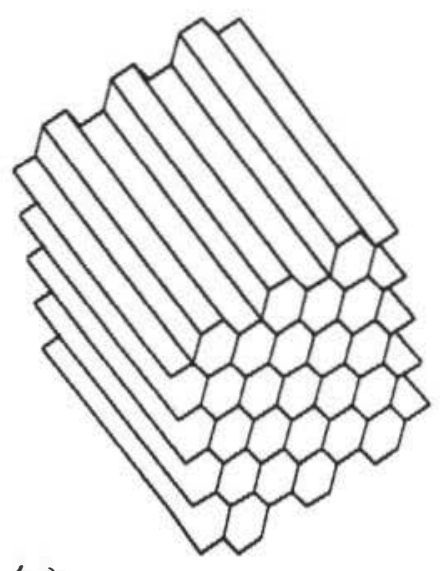

(a)

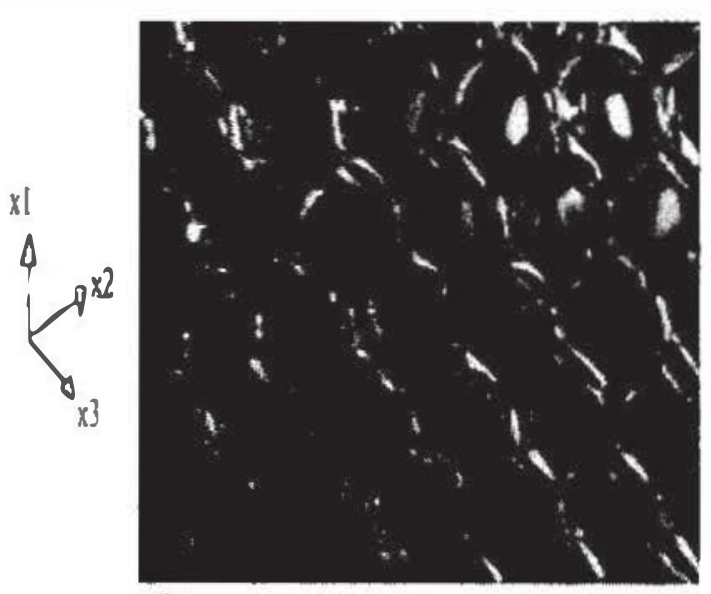

(b)

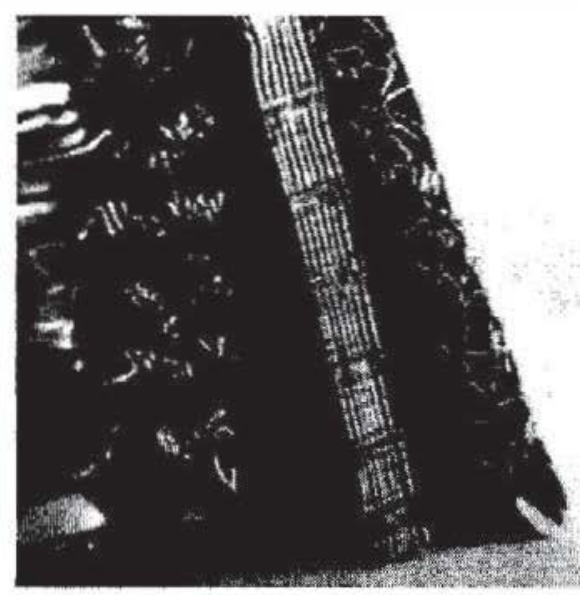

(c)

Figure 3, post test photograph of the honeycomb 
A summary of expcrimental results for the three directions is shown in Figure 4. (Valucs in the out-of-plane $\times 3$-direction have a different scale.) Significant differences between static and dynamic results are only found in the out-of-plane crushing [21]. According to Wierzbicki [22], the mcan crushing pressure depends only on the flow stress and the so-called relative cell thickness. Increases in the mean crushing pressurc could, then, be attributed to a different flow stress under dynamic loading. However, we consider that the factor primarily responsible for this enhancement of the crushing strength remains an open question. Possible factors have been mentioned in theoretical works in the open literature. For examplc, a dynamic buckling model of an elastoplastic column [23] has shown that the buckling mechanism is stabilised by effects due to lateral inertia, even when the initial imperfection is significant. Thcre exist also a shock model bascd on structural inertia effects which has successfully explained a similar phenomenon observed in the results of woods [24], and a model based on air trapped in the cells [25].

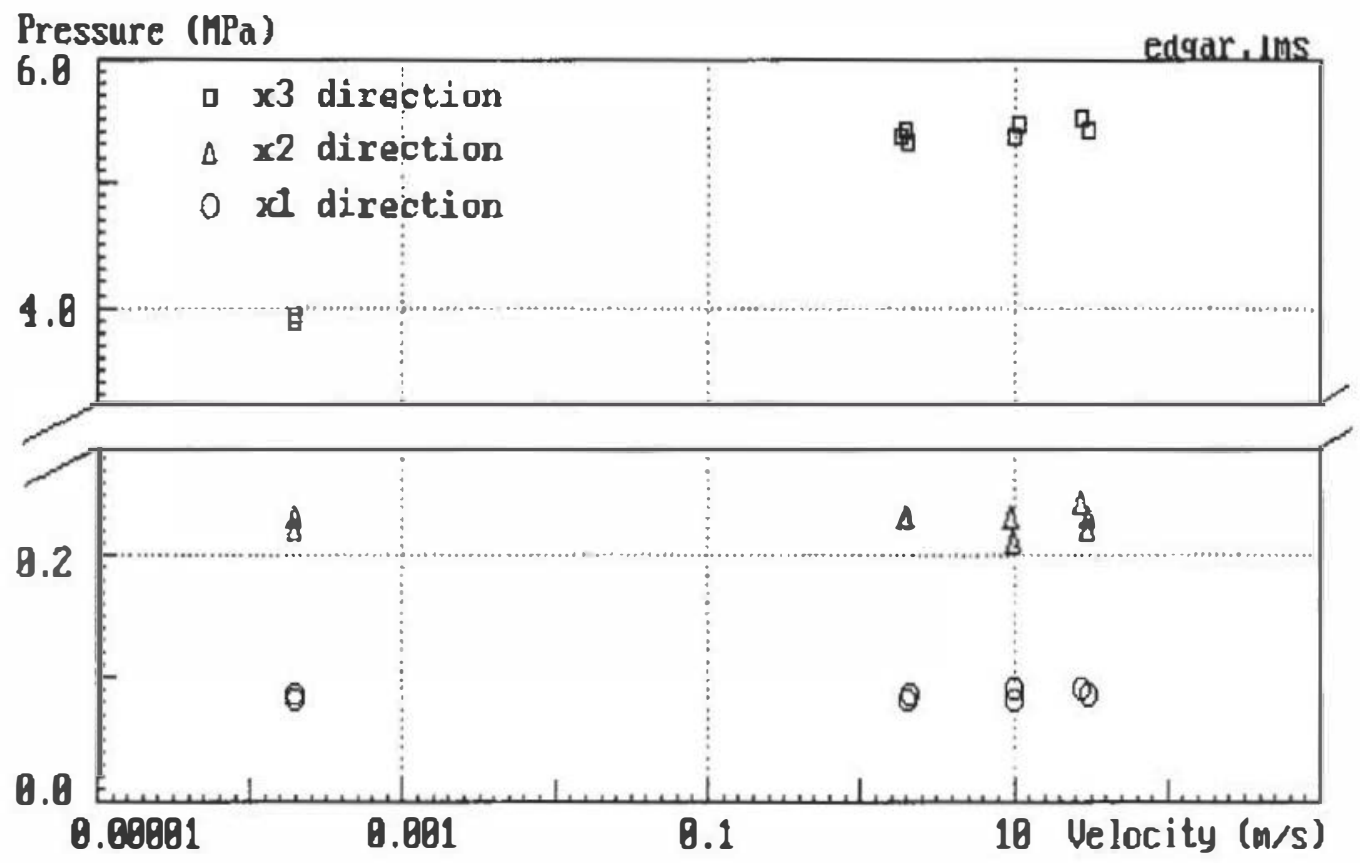

Figure 4. Rate sensitivity of honeycombs

For the aluminium foam, cylindrical specimens are machined from cylinder of diameter of $28 \mathrm{~mm}$ given by the industry. The expcrimental data shows an important dispersion. Post-test examination reveals holes in the middle of the specimen which appears to be due to manufacturing process. (Figure 5a). Anyway, the general tendency has been drawn for several foam of different cell size from $0.2 \mathrm{~mm}$ to $0.6 \mathrm{~mm}$. Figure $5 \mathrm{~b}$ show that the rate sensitivity is not influcnced by this parameter.

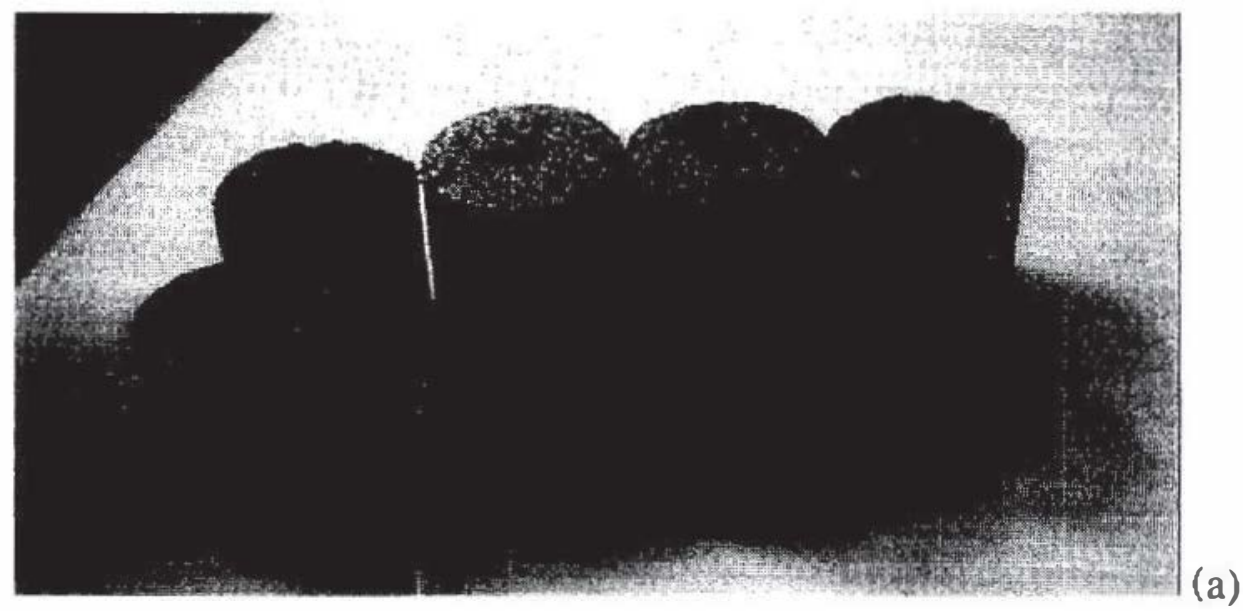




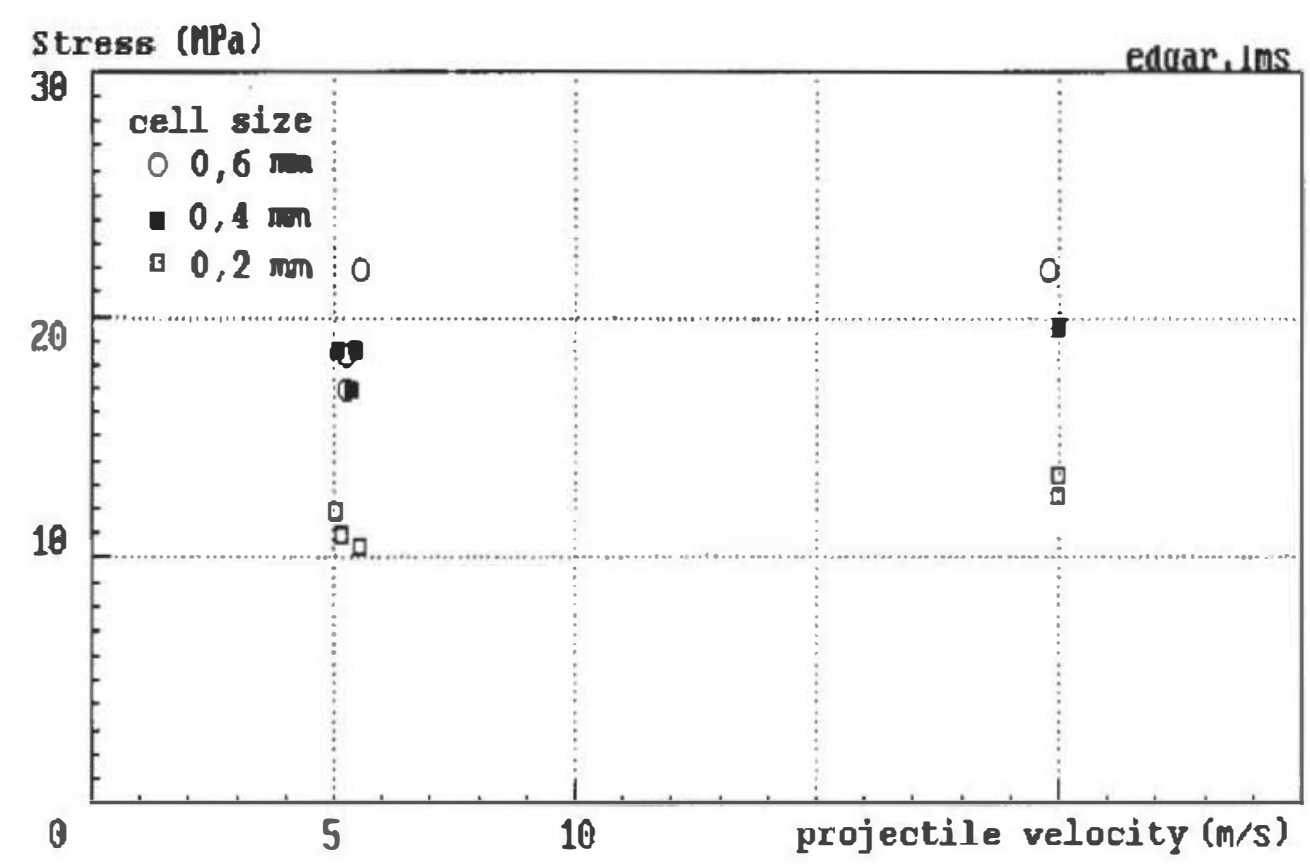

(b)

Figure 5 (a) specimen inhomogeneity, (b) ratc scnsitivity

\section{References}

1. B. Hopkinson, Phil. Trans. Roy. Soc., A213 (1914), 437-452

2. R.M. Davies, Phil. Trans. Roy. Soc., A240 (1948), 375-457.

3. H. Kolsky Proc. Phys. Soc., B62(1949), 676-700.

4. H. Zhao and G.Gary, Int. J. Solid. \& Structure. 33(1996), 3363-3375.

5. A.F. Conn, J. Mech. Phys. Solids, 13 (1965) 31 1-327.

6. A. Marchand and J. Duffy, J. Mech. Phys. Solids. 36 (1988) 251-283.

7. G.I. Taylor and M.A. Quinney, Proc. Roy. Soc. A, 143 (1934) 307-326.

8. J.D. Campbell and W.G. Ferguson, Phil. Mag., 81 (1970) 63-82.

9. S. Tanimura, in Proc. ler Int. Symp. Impact Engng., (Ed. I.Maekawa), Japan, 18-26. 1992.

10. H. Zhao, Mater. Sci. \& Engng. A320 (1997) 95-99.

11. H. Zhao, Cement \& Concrete Composites, 20 (1998) 293-299.

12. H. Zhao, Polymer, 39 (1998), 1103-1106.

13. H. Zhao, Polymer testing, 16 (1997), 507-516.

14. H. Zhao and G.Gary, J. Mech. Phys. Solids, 43(1995), 1335-1348.

15. H. Zhao and G.Gary, Composite Sci. \& Technol. 57(1997), 287-292.

16. J.D. Campbell, and J. Duby, Proceeding of Royal Society of London, A 236 (1956), 24-40.

17. B. Lundberg and A. Henchoz, Experimental Mechanics. 17 (1977), 213-218.

18. H. Zhao and G. Gary, J.Mech.Phys.Solids. 45(1997), 1185-1202.

19. G. Gary and H. Zhao, in Proc. IUTAM symposium on Nonlinear wave in solids, (Ed. J.L.Wegner), Appl. Mech. Rew. Edition. 185-189, 1994.

20. Klintworth, J.W., and Stronge, W.J., Int. J. Mech. Sci. 30(1988), 273-292.

21. H. Zhao and G. Gary, Int. J. Impact Engng, 21 (1998), 827-836.

22. T. Wierzbicki, Int. J. Impact Engng., 1 (1983),157-174.

23. G. Gary, Int. J. Impact Engng, 1, (1983), 357-375.

24. S.R. Reid, and C. Peng Int. J. Impact Engng, 19 (1997), 531-570.

25. P. Seggewiss, Master's thesis, Bundeswehr University, Munich (1996). 